\title{
Toxic cloud over Seveso
}

\author{
The fall-out from last month's explosion in Italy \\ involves more than dust, as Alastair Hay points out
}

$\mathrm{O}^{\mathrm{N}}$ JULY 10, an explosion at a chemical factory in the North Italian town of Seveso released a cloud of vapour which contaminated the surrounding area. The vapour, a chemical cocktail consisting primarily of trichlorophenol (TCP), also contained an extremely toxic by-product, TCDD $(2,3,7,8$ - tetrachlorodibenzopara - dioxin), a virulent poison.

It happened six and a half hours after the plant, belonging to Givaudan ICMESA, a subsidiary of Hoffman-La Roche, had closed down for the weekend. There was a "runaway reaction" in the reactor producing trichlorophenol. The pressure increased as the reaction became exothermic, and reached the critical limit, blowing the safety valve and thus discharging the reactor contents. The valve, situated outside the plant, discharged the hot vapour directly into the atmosphere. When the solvents evaporated, trichlorophenol crystals and $2 \mathrm{~kg}$ of TCDD, in the form of dust, were precipitated south of the factory over an area inhabitated by some two thousand people.

Local police were informed of the explosion on the day that it occurred; the following day the mayor of Seveso was told; and on Monday, July 12, ICMESA notified the local authorities of areas bordering on Seveso. A statement was issued by these local officials, warning against the consumption of fruit and other crops from the area surrounding the factory. On July 15, the first animal deaths were reported. The first reports of children suffering from skin rashes came a day later. By July 22, when over thirty people were reported to be showing symptoms of burns and poisoning, local authorities were still insisting that there was no cause for panic. No general evacuation had been planned.

Not until two weeks after the explosion was TCDD first identified, by a provincial diagnostic centre. The identity of the dioxin was confirmed by Givaudan three days later, on July 26. Local officials had meanwhile been alerted to the seriousness of the situation by the ICMESA management, and on Tuesday, July 27 , fully $2 \frac{1}{2}$ weeks after the explosion, evacuation began, at first only of children. Since then the known area of serious contamination has grown severalfold, and by the middle of last week over 800 people had been evacuated from this zone. Another 1,300 children had been evacuated, as a precautionary measure, from the area outside that of immediate contamination.

\section{Delayed action}

Only after it had been established that TCDD had also been released in the vapour cloud did the authorities realise the need for urgent action. Up to this point, the information supplied to them by the ICMESA management had implied that the worst component of the vapour was trichlorophenol. This undoubtedly led the local authorities to believe that the situation, although serious, did not warrant a general exodus from the contaminated area.

It is this delay which has given cause for concern, particularly in view of the known toxicity of the dioxins. Experimental evidence is available of the effects of TCDD on a range of animals, and is to be found in the US National Academy of Sciences (NAS) document Effects of Herbicides in South Vietnam. A single dose of this dioxin is lethal in guinea pigs at a concentration of $0.6 \mu \mathrm{g} \mathrm{kg}^{-1}$. In male rats the lethal dose is $22 \mu \mathrm{g} \mathrm{kg}^{-1}$; in rabbits $115 \mu \mathrm{g} \mathrm{kg}^{-1}$; and in humans, it has been calculated to be less than $5 \mathrm{mg} \mathrm{kg}^{-1}$. This means that the toxicity of TCDD can be compared to that of strychnine.

Clinical signs of TCDD poisoning include atrophy of the kidney; necrotic changes of the liver; ulceration of the stomach; haemorrhages in the gastrointestinal tract and other organs; and atrophy of the thymus and other lymphoid organs and tissures. The latter changes are those most commonly observed.

Teratogenicity of TCDD has been demonstrated in mice, although evidence of teratogenic effects in other animals is more equivocal. According to Neubert et al. (Environ. Health Perspectives, Exp. Issue No. 5, 67-80; 1973), when TCDD was given to mice daily on days 6 to 15 of pregnancy, at least $50 \%$ of the progeny exhibited kidney anomalies at concentrations of 1-3 $\mu \mathrm{g} \mathrm{kg}^{-1}$; death occurred at concentrations of $7 \mu \mathrm{g} \mathrm{kg}^{-1}$.

Reports from Seveso confirm that 500 people are being treated for poisoning. Many are showing symptoms of kidney and liver malfunction. Others from the area affected by TCDD fallout have chloracne, a persistent and disfiguring form of acne associated with contact with chlorinated compounds. If treated, the acne may clear up in six months. There is evidence,

\section{Sorry, for copyright reasons some images on this page may not be available online}

however, of a worker in a chemical factory producing chlorophenols who is still disfigured 15 years after exposure to the chemicals.

\section{Not the first time}

As the painful assessment begins of the effects of the dioxin contamination, evidence has accrued almost daily of chemical explosions involving trichlororophenol production which have already occurred and which were similar to the one at the ICMESA plant.

The first accident occurred in 1953 at the Ludwigshafen works of the Badische Anilin und Soda Fabrik AG (BASF) in Germany. Fifty-five workers were exposed to dioxin, all of whom developed chloracne. Twentyone developed symptoms of systemic poisoning, including damage to the liver, kidney and spleen; the heart, respiratory tract, eyes and nervous system were also affected. Five years after the accident, a worker engaged on repair work on the site developed symptoms of dioxin poisoning; nine months after the appearance of the first symptoms, this worker died from an inflammation of the pancreas. Following medical advice, BASF later stopped production of trichlorophenol.

In 1963, at the Philips Duphar complex in Amsterdam, an explosion released between 30 and $200 \mathrm{~g}$ of dioxin into the factory hall. Fifty people were affected, at least ten of whom are still suffering from skin complaints. Four workers died within two years of the accident, but there is no proven connection between their deaths and dioxin poisoning. After an unsuccessful attempt to remove dioxin from the factory walls, the firm closed down the trichlorophenol plant for ten years. When information on dioxin contamination had been reviewed, the only course of action open to the company was to dismantle the plant brick by brick working from the inside outwards. The rubble, embedded in con- 
crete, was eventually dumped into the Atlantic.

At the Coalite and Chemical Products plant at Bolsover, Derbyshire (UK), seventy-nine men developed chloracne following an explosion at the trichlorophenol plant in 1968. Since the Seveso accident, this firm and the West German firm of Bayer of Leberkusen have both temporarily ceased production and are reviewing their manufacturing procedures.

The most disturbing reports relating to dioxin poisoning, however, are undoubtedly those from Vietnam. Increasing criticism of the American use of herbicides in the war in Indochina resulted in the National Academy of Sciences conducting a thorough investigation. The report of their findings, published in 1974, has been criticised over its interpretation of the data concerning deaths and birth defects in communities sprayed with herbicides. In an introduction to the report, Dr Philip Handler, the NAS President, claimed that no definite connection existed to confirm findings of herbicideinduced birth defects or deaths.

The NAS report itself does, however, contain considerable information about the effects of herbicides and the contaminant TCDD on humans, animals and vegetation in Vietnam. One anthropologist who submitted evidence to the NAS study, Dr Gerald Hickey of the South-East Asia Programme of Cornell University, has reported evidence of deaths from among the children of the Montagnard peoples of South Vietnam, deaths directly related to herbicide spraying. The first-hand interviews he conducted with Montagnard villagers revealed the additional evidence that other children had shown symptoms such as skin rashes, diarrhoea and abdominal pains.

Hickey was cautious in attributing these effects directly to TCDD; the evidence is more circumstantial. During the Vietnam war, the Americans repeatedly sprayed these mountainous areas of South Vietnam, inhabited by the Montagnard people, with the herbicide "Agent Orange", a $50: 50 \mathrm{mix}-$ ture of the n-butyl esters of 2,4-D (2,4-dichlorophenoxyacetic acid) and 2, 4, 5-T (2,4,5-trichlorophenoxyacetic acid). The dioxin TCDD is a contaminant present in 2,4,5-T at levels variously estimated at between 0.07 and 50 p.p.m.

Although the NAS repont claimed that no evidence is available to substantiate herbicide-induced birth defects in humans, the Italian authorities are currently paying serious attention to the advice of a Vietnamese doctor. Professor Ton That Tung of the Viet Duc Hospital in Hanoi insists (in Vietnamese Studies, 29, 53-81; 1971) that such evidence is available.

\section{Unanswered questions}

Certainly the assembled evidence points to some unanswered questions. Because previously recorded accidents at other trichlorophenol-producing plants had released TCDD, the chance existed that the same would be true in any accident at Seveso, and the authoritites might have expected to have been informed accordingly. But even in the unlikely event that the ICMESA management was unaware of the historical evidence pointing to this danger, simple theoretical knowledge of the factors favouring TCDD production should have alerted them to the possibility of dioxin contamination. Moreover, the plant's safety valve was situated outside the plant, allowing a discharge of vapour directly into the atmosphere. This served to protect the plant itself from the vapour, but did so at the cost of serious contamination of the surrounding countryside.<smiles>Clc1cccc(Oc2ccccc2Oc2ccccc2Cl)c1</smiles>

TCDD

\section{(2,3,7,8-tetrachlorodibenzopara-dioxin)}

TCDD is produced as a by-product during the alkaline hydrolysis of tetrachlorobenzene with methanolic sodium hydroxide to form 2,4,5-trichlorophenol (i).

Trichlorophenol is both the industrial precursor of 2,4,5-T (2,4,5-trichlorophenoxyacetic acid), a herbicide normally used in esterified form as the butyl ester (2), and an intermediate product in the manufacture of hexachlorophene, an antibacterial agent added to soaps, shampoos, deodorants and toothpastes.

The hydrolysis of tetrachlorobenzene is carried out at high temperatures and under pressure. This reaction, if not very carefully controlled, is favourable to the formation of TCDD, the most common chlorodibenzoparadioxin present in $2,4,5-\mathrm{T}$. Other toxic polychlorodibenzoparadioxins are also produced in the manufacture of chlorinated phenols.

Theoretically, at least 75 different chlorodibenzoparadioxins can be predicted having one to eight chlorine atoms attached to the two benzene rings. At least ten have been synthesised, and one or two more have been found in food, animal feeds and 2,4,5-T.

Hexachlorophene is prepared by the condensation of two molecules of 2,4,5trichlorophenol with formaldehyde in the presence of concentrated sulphuric acid (3). The preparation procedure has been improved, and the Givaudan Corporation hold the US patents Nos. $2,435,593$ (1948) and 2,812,365 (1957).

\section{Properties of TCDD}

Like other chlorodioxins, TCDD is stable to heat, acids and alkali; a temperature of $800{ }^{\circ} \mathrm{C}$ is required for thermal decomposition. TCDD is virtually insoluble in water $(0.0002$ p.p.m. $)$, only slightly soluble in fats (44 p.p.m. in lard oil), more soluble in hydrocarbons (570 p.p.m. in benzene), and at its most soluble in chlorinated organic solvents (1400 p.p.m. in ortho-dichlorobenzene).

Uptake of TCDD occurs slowly in plants (oats and soybeans). No accumulation above external concentration occurs, however, and plants grow to maturity (A. R. Isensee and G. E. Jones, Agric. Food Chem., 19, 1210-1214; 1971).

TCDD is almost immobile in soil. Even in very porous soil it remains close to the point of application (P. C. Kearney et al., Environ. Health Perspectives, Exp. Issue No. 5, 273-278; 1973).
Benzene $\longrightarrow$ Tetra-chlorobenzene $\longrightarrow$ TCDD

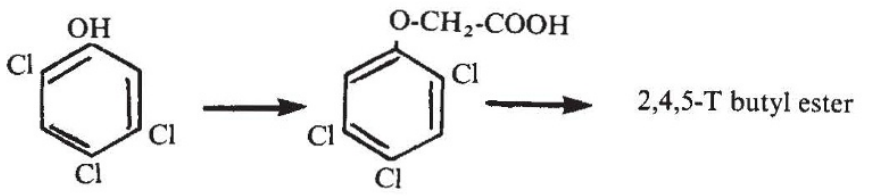

2,4,5-trichlorophenol

$$
2,4,5-\mathrm{T}
$$<smiles>Cc1cc(Cl)cc(Cl)c1</smiles><smiles>Cc1cc(Cl)ccc1Cl</smiles><smiles>Cc1cc(Cl)ccc1O</smiles>

2,4,5- trichlorophenol 
The question of decontamination is now presenting Givaudan, Roche and the Italian government with serious problems. An Italian government commission recommended removal of topsoil to a depth of $10 \mathrm{~cm}$ in an area of 280 acres, the dismantling of all buildings in the Seveso area and the total disruption of all wildlife. These recommendations may take up to three years to implement. The sheer volume of soil to be processed and the number of buildings involved will create enormous technical problems of disposal. Great care will have to be taken to avoid further contamination by TCDD when material is removed from Seveso.

The British firm of Cremer and Warner have been retained by Givaudan to help in the task of decontamination. Cremer and Warner are chemical engineers specialising in the environmental safety aspects of industrial pollution. Data already accumulated indicate that the intensity of contamination does not conform to any uniform pattern, and the feeling is that it would be premature to implement the Italian commission's proposals, at least until potential alternatives are considered.

But no one doubts that a satisfactory policy for accident prevention and control can possibly be formulated if vital information is withheld from those whom it may affect most directly. In Seveso, the local mayors did make attempts to find out what was actually being produced at the ICMESA plant. But that was four years ago. Only last year did Givaudan finally provide some information. No mention was made of the dioxin risk, and therefore no safety measures were suggested. Even now there is conflicting information about the processes for which the ICMESA works were designed. One senior Roche executive has said the plant was producing trichlorophenol for the manufacture of the herbicide 2,4,5-T; another spokesman claimed that the plant was making trichlorophenol for the manufacture of hexachlorophene at another site.

\section{Few unaffected}

Few people have been uninvolved by the actions of the Roche subsidiary. Scientists and engineers at the Seveso plant failed to predict the extent of dioxin contamination and its spread over the countryside. Workers at the factory demanded to know of any dangers involved. Management did not inform them until two weeks after the explosion. Local residents knew nothing of the real hazards of the contamination. The medical profession, lacking an antidote, must give only symptomatic treatment. Pregnan t women, agonising over the teratogenic effects of TCDD, must decide with little firm guidance from the Church whether to undergo abortions. Ecologists cannot predict the long term effects of dioxin contamination. The authorities know that the decontamination proposals themselves are at best a mixture of policies adopted at previous accidents, leavened with a good deal of hope.

The suggestions being made now involve at the very least the implementation of strict codes of practice, to be adopted between industrial concerns and the local authorities to which they bear a great measure of responsibility. Such codes would include detailed procedures to be followed in the event of an accident. As for the withholding of information, few are accepting the obvious convenience this represents for manufacturers as a satisfactory explanation. Many are saying that with all the facts more freely available, it may, for example, be decided that the risks involved in producing trichlorophenol outweigh the necessity of a 2,4,5-T weedkiller-or a TCP mouthwash. Only the inquest now to come will reveal whether some sort of political solution is needed to ensure that the necessary information is available and to prevent a recurrence of this kind of disaster.

\section{Europe's ageing research staffs}

\section{Mike Duckenfield reports from Stockholm on the problem of an "unhealthy" age profile among researchers and teachers}

\section{WITH one or two exceptions,} notably Finland where spending is to be increased from $1 \%$ to $1.7 \%$ of the GNP during the next five years, research budgets in most Western European countries are having a struggle to keep pace with rising costs. Not only is government spending being cut back or slowed down, but what funds there are available are being affected by an incremental drift of salaries as young staff get older and, as in Britain and the USA, increasing unionisation. Even in Norway, where unemployment is well below $2 \%$ and economic growth at a steady $7 \%$, the prospects for those wanting research jobs are very slim.

Graduate unemployment is a problem in itself, but there is also another side to the coin: the likely prospect of universities and research institutes in most nations losing a generation of teachers and researchers during the next 15 years due to the lack of job opportunities. The problem, in short, is that the universities are now moving into the shadow of the massive expansion of higher education which took place in the 1960s. Due to this boom the average age of teachers and researchers is now very low, retirements are relatively few and future openings for new blood and ideas drastically diminished. According to academics in several countries, promotion, mobility and possibly even creativity are all likely to suffer.

The problem of an "unhealthy" age profile among researchers and teachers is beginning to be studied in nations ranging from France to Norway. Due to large scale recruitment in the middle and late $1960 \mathrm{~s}$, too large a proportion of staff are now only at the beginning of their careers. A recent Federal German survey shows that while $45.9 \%$ of professors and senior lecturers in 1966 were over 50 years old and only $22.3 \%$ under 40 , corresponding figures for 1972 were $28 \%$ and $30.5 \%$. In addition, while other teaching staff under 35 accounted for $17.4 \%$ of the total in 1966, six years later the figure was $27.3 \%$.

In Britain, too, the average age of university teachers has fallen significantly; now $63 \%$ of academic staff are under $40,26 \%$ are under 30 and $13 \%$ over 50 . In Norway $18.8 \%$ of staff are over 50 compared with $43.7 \%$ under 35, while a survey of French research workers in the Centre National de la Recherche Scientifique showed the average age of those engaged in mathematics was 28 years and 7 months and those in physics and chemistry 34 years and 5 months. In Sweden as many as two-thirds of researchers in some branches of social science are under 35.

With comparatively young staff holding most of the senior positions, future promotion prospects are well below normal. A report prepared for the Council of Europe by Gert Elstermann, academic director of the University of the Saarlands, says that the annual replacement demand for teachers in Federal German universities and colleges up to 1990 will remain much the same as it is at present in law and the social sciences. For other subjects it will stay unchanged until the mid-1980s. Similarly, in Norway prospects for the next 15 years suggest annual recruitment levels below those of any year since the early 1960s. In 